\title{
Effects of Perceived Procedural Justice and Exchange Ideology on Employees' Affective Commitment: Evidence from Saudi Arabia
}

\author{
Mona N. Moussa ${ }^{1}$ \\ ${ }^{1}$ College of Business Administration, Human Resource Management Department, University of Business \& \\ Technology, Jeddah, Saudi Arabia \\ Correspondence: Mona N. Moussa, College of Business Administration, Human Resource Management \\ Department, University of Business \& Technology, Jeddah, Saudi Arabia. Tel: 966-5332-3036. E-mail: \\ m.moussa@ubt.edu.sa
}

Received: May 17, 2013

Accepted: July 3, 2013

Online Published: July 12, 2013

doi:10.5539/ijbm.v8n15p81

URL: http://dx.doi.org/10.5539/ijbm.v8n15p81

\begin{abstract}
This paper examined how perceived procedural justice and exchange ideology affect employees' commitment in Saudi private sector companies. A self-administered questionnaire was distributed to a random sample of 104 Saudi employees. Descriptive statistics, reliability analysis and regression analysis, were used to analyze the data. The results revealed that perception of organizational procedural justice influenced employees' commitment towards their organizations. Employees with high exchange ideology perceiving procedural justice as unfair who fear the loss of such fairness would consider staying with the company to be risky and would intend to leave were not affectively committed toward their organizations, while those perceiving procedural justice with low exchange ideology had a moderate or no relation with affective commitment.
\end{abstract}

Keywords: perceptions, procedural justice, exchange ideology, affective commitment, Saudi Arabia

\section{Introduction}

One of the main concerns for many companies today is staff retention. Employees leaving their organizations or intending to leave their organizations are costing these organizations substantially. Because of this adverse effect on organizations, Griffeth and Hom (1995) indicated that employees' commitment to their organizations and intentions to leave are two important predictors of the turnover of employees.

Saudi Arabia is witnessing an unprecedented unemployment phenomenon. One main reason for such a phenomenon is that the education system and the labor market are poorly aligned. The curriculum content is largely controlled by a religion-based authority whose members are not equipped with the skills to judge the requirements of the market demand. In addition, many Saudi nationals are not prepared or motivated to meet the requirements of the private sector. Furthermore, current policies do not address concerns of employers as the needs to hire nationals differ from one industry to another (Fakeeh, 2009).

Most Saudi nationals prefer to work in the public sector because of relaxed working conditions and high compensation packages. This leaves the private sector in a difficult position to meet established targets of hiring nationals. Today, the private sector suffers from a high turnover and less emotionally committed nationals. Whether the Saudi nationals intend to leave private organizations or remain with them, low commitment can be detrimental because of lack of productivity and lower financial returns.

As the literature review shows in the next section, employees' perceptions of procedural justice are an important factor that affects employees' commitment. Perceived justice relates to how employees perceive the level of fairness associated with their performance and its outcomes, e.g., rating, promotion and pay increments.

Study findings suggest that when employees perceive a high level of performance fairness they become more committed towards their organizations and performance is improved, Cowherd and Levine (1992). When employees are in doubt of organizational justice, they simply lose interest in the organization and demonstrate an unwillingness to pursue organizational goals through concurrent absenteeism and unusual behavior, Cropanzano et al (1997).

Companies survive and prosper when they succeed in retaining and maintaining their skilled employees. Employee loyalty inevitably becomes a crucial item for companies to remain at and maintain a competitive 
advantage. Delivering superior value to employees through fair organizational processes and procedures helps in retaining and increasing employees' loyalty.

The Saudi culture in many companies has been identified as a repelling environment for Saudis, forcing many Saudis to quit their jobs, and for others to be less committed (Hay Group, 2010). This study examines possible effects of procedural justice and exchange ideology on employees' commitment in the context of Saudi private companies.

The remainder of this study is organized as follows:

The next section reviews the literature review. The third section outlines the research methodology, while the fourth section reports on the results. The fifth section discusses the results, their implications and limitations.

\section{Literature Review}

There are several studies that have examined some issues related to the effects of different factors on employees' commitment. My reviews of these studies are organized are under three headings:

The first reviews some studies on commitment. The second deals with some studies of organizational justice. The third reviews some studies dealing with social exchange ideology.

\subsection{Commitment}

Early work by Porter et al. (1974) identified three characteristics of commitment. They include strong belief in and acceptance of the organization's goals and values, willingness to exert considerable effort on behalf of the organization, and a definite desire to maintain organizational membership. Porter's et al. study measured organizational commitment and job satisfaction relating to turnover among 60 recently employed psychiatric technician trainees. The study was a longitudinal study conducted over about an 11 month period. The results showed that a significant relationship existed between certain employee attitudes and turnover, as well as viewed commitment as a construct consisting of three dimensions. These dimensions include affective commitment, continuance commitment, and normative commitment. Affective commitment relates to emotional attachment of an employee to the organization. Continuance commitment deals with an employee's intrinsic obligation due to organizational socialization pressure to stay with the organization. Finally, normative commitment refers to the employee's choice to stay on the job or change it with the possibility of suffering a loss.

Rhoades et al. (2001) conducted three studies to examine the interrelationships of work experiences, perceived organizational support, affective commitment and employee turnover. The studies surveyed a random sample of 376 employees from many organizations. The first study found that POS (Perceived Organizational Support) mediated positive associations of supervisor support, procedural justice, and rewards with affective commitment. The second study examined changes of POS (perceived organizational support) and affective commitment in retail employees over a two-year period with a sample of 333 employees. The third study found a negative relationship between POS (perceieved organizational support) and voluntary turnover that was mediated by affective commitment in retail employees with a population of 1,124. All three studies have provided evidence that employees working in favorable working conditions operate via POS (perceived organizational support) to increase affective commitment, which in turn decreases employee withdrawal.

Allen and Meyer (1990) developed an instrument that measures the above three dimensions. The instrument initially had eight items for each dimension. Meyer and Allen (1991) modified the instrument to have 18 items in total, where each dimension is represented by six items.

Mowday et al. (1979) pointed out that affective commitment describes the emotional attachment between the employer and employee reflecting employees' reciprocating benefits in exchange for the benefits offered by the organization. Such employees prefer to stay with the organization out of desire and not because the organization is their reason for living.

The Moorman et al (1998) study findings reflect the fact that the perception of the employee regarding the situation matters if the employee perceived the situation as the benefits outweigh the costs, which reflects a high level of exchange ideology.

Shore and Wayne (1993) suggested that employees' perceptions of perceived organizational support develop feelings of obligation to the employer. This, in turn, enhances employee's work behavior. The study had a sample of 383 participants and their managers. Results of the study showed affective commitment and POS (perceived organizational support) were positively related to organizational citizenship. Their results support the social exchange view of Eisenberger et al, (1986). 
Taylor and Lind (1992) considered it irrelevant when exchange ideology is weak since employees will never demonstrate affective commitment; Eisenberger et al, (1986) used the exchange ideology as the moderator that will examine manager - affective commitment and its relation to employee perceptions of procedural justice.

Leung and Stephen (2001) argued that cross-cultural studies are important for justice theory development. Since most of the research developed is related to Euro-American cultural boundaries, for justice theories to become more generalized further universal studies must be conducted in other regions of the world.

Elamin and Alomain (2011) examined the influence of perpetual organizational justice on job satisfaction and self-perceived performance in Saudi Arabia. The study used a sample of 793 employees selected randomly from different organizations to collect data through a questionnaire. They used regression and correlation analyses to examine the data. The findings of the study revealed that perceptions of organizational justice influenced job satisfaction for both Saudi and non-Saudi employees. The justice dimensions had a significant influence on self-perceived performance. The distributive justice predicted self-perceived performance for foreign workers, while procedural justice had a negative effect on it.

\subsection{Procedural Justice}

Cropanzanoa and Greenberg (1997) identified three types of justice. They are distributive, procedural, and interaction justice. Distributive justice is more related to economic outcomes (fairness of resource allocations)while organization procedural justice is more related to procedures and emotional outcome of performance. Cowherd and Levine (1992) realized that procedural justice is reported to be a strong determinant of performance while Barling and Philips (1993) realized that procedural justice was a strong determinant of the level of affective commitment. Interaction justice results from the crossing of the other two types of justice. Witt et al (2001) confirmed that procedural justice is the most appropriate for explaining variance in organizational commitment.

Moorman et al (1998) examined the conceptual model to identify the roles of perceived organizational support in the relationship between employees' distributive justice perception and organizational citizenship behaviors (OCB), based on social exchange theory. This study was tested among 93 MBA students, by using mediated regression analysis; the findings suggested that POS (perceived organizational support) acts as a mediator between distributive justice perceptions and OCB (organizational citizenship behavior).

Shore et al. (1995) studied perceptions of 231 managers and 339 subordinates and found that organizational citizenship behavior predicted manager-rated affective commitment that was positively related to several outcomes such as managerial potential and promotion.

Ponnu and Chuah (2010) investigated the relationship among organizational justice, organizational commitment and turnover intention of Malaysian employees. Results of perceptions of procedural and distributive justice were significant contributors in explaining organizational commitment and turnover intention. In addition, the results show that turnover intentions have an opposite relationship to affective commitment.

\subsection{Social Exchange Ideology}

Social exchange theory was introduced by Blau (1964) to suggest that individuals interact socially when they have rational self-interest. Eisenberger et al (1986) developed a further argument regarding the social exchange theory to suggest that employees repay organizations by becoming affectively committed towards them.

Korsgaard et al. (1995) suggested that it is important for employees to perceive their organizations as fair organizations when it comes to performance ratings, pay, and promotions. Exchange ideology reflects self-serving and negativity bias; if employees interpret supervisor treatment as unfair, this would create a feeling of less obligation towards fulfilling the requirements of the job as demanded by the supervisor.

Cropanzano et al. (1997) suggests that lack of such predictable support would only lead employees to take crucial decisions regarding their future in such organizations. Their loyalty will be misplaced and they would eventually withdraw emotionally from this relationship. The work of Masterson et al (2000) confirmed that there is an important element to consider when regarding the exchange ideology; which is the quality of the exchange; such as allowing employees to make their own decisions and work with autonomy under constructive feedback from their supervisors. Shore and Shore (1995) believe that employees being exposed to procedural fairness will consider their organizations as supportive.

Witt et al. (2001) included 143 employee and their immediate supervisors from a private sector company. The results of the study indicated that employee's perceptions of procedural justice were related to supervisor-rated affective commitment behaviors for employees with a strong exchange ideology. While employees that were 
indifferent to fair exchange did not change their affective commitment towards their organizations regardless of the level of perceived organizational justice.

\section{Research Methods}

\subsection{Sample}

The researcher used a random selection procedure to sample 300 Saudi nationals working for different private organizations in the area of North Jeddah. The human resource director of one private company allowed our team to select employees and their supervisors randomly from different departments. The sample represented top, middle and bottom levels of management with their subordinates. A self-administered questionnaire was distributed to the sample by a team of researchers working at the university as interns for the company.

The researcher received back 140 questionnaires, representing a response rate of about 46 percent. Nevertheless, 36 questionnaires were excluded from the analysis either because of incomplete data or the respondents were non-Saudi nationals. This left 104 questionnaires suitable for analysis. Thus, the final response rate was about 32 percent.

\subsection{Development of the Questionnaire}

The researcher used a questionnaire that contained four parts. The first part dealt with respondents' demographic data such as age, gender, nationality, experience, and so on. The other parts contained the scales used to measure the research variables as explained below. The questionnaire was assembled in English and then translated into Arabic and back to English to ensure face validity.

\subsection{Research Model and Hypotheses}

Based on the literature review, this paper used the following representation of theoretical model.

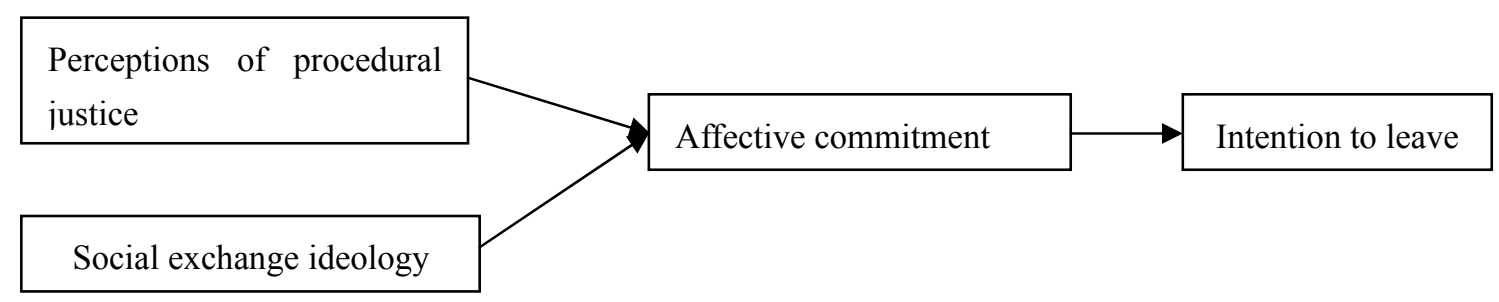

The model contains four variables. The far left two variables represent the cause variable for the affective commitment. Affective commitment, in turn, affects employees' intention to leave. The models depict the relationships among these variables which are used as the basis for developing the research hypotheses. As employees perceive high level of fairness, they tend to have high affective commitment. Accordingly, the first hypothesis is stated as follows:

$\mathrm{H}_{1}$ : There is a positive relationship between employees' perceived procedural fairness and employees' affective commitment.

The model also attributes high affective commitment to high exchange ideology. This means that employees with high level of exchange ideology tend to have high level of affective commitment. Accordingly, the second research hypothesis is stated as follows:

$\mathrm{H}_{2}$ : There is a positive relationship between employees with high exchange ideology and affective commitment towards the organizations where they perceive their environment (procedural justice) as unfair.

Committed employees usually do stay with their organizations. Accordingly, one would expect that high commitment is negatively related to intentions to leave. Thus, the third research hypothesis is stated as follows:

$\mathrm{H}_{3}$ : There is a negative relationship between affective commitment and intention to leave.

\subsection{Measures}

\subsubsection{Affective Commitment}

This variable was measured by a six-item scale developed by Shore et al (1995). Respondents rated each of the six items on a five-point Likert scale ranging from 1 (strongly disagree) to 5 (strongly agree). Thus a higher score on this scale indicates high affective commitment. A reliability measure of the internal consistency of the items was very high using Chronbach's alpha (alpha $=0.91$ ). 


\subsubsection{Exchange Ideology}

This variable was measured by an eight-item scale developed by Eisenberger et al (1986). Each item was rated on a five-point Likert-type scale ranging from 1 (strongly disagree) to 5 (strongly agree) with higher score indicating strong exchange ideology. A factor analysis of the eight items resulted in the exclusion of three items from the scale. The reliability coefficient was at an acceptable level (alpha $=0.73$ ). Thus, five of the original eight items were used to calculate the score for this variable for the regression analysis.

\subsubsection{Procedural Justice}

This was measured by a shorter (6 item) version of Eisenberger et al (1986) was used to measure the perception of procedural justice. People who had higher scores had more perception of procedural justice. The Chronbach's Alpha reliability coefficient of the six-item scale was (0.85).

\subsubsection{Control Variables}

These are the demographic variables that could affect the influence of the two main independent variables on commitment. They include respondents' age, gender and length of experience. Harrison and Hubbard (1998) and Witt et al (2001) showed that years of experience develop affective commitment towards the organization, while Abdullah and Shaw (1999) found that affective commitment increases as age increases. Scandura and Lankau (1997) and Witt et al. (2001) indicated that women were more inclined to be committed than men.

\subsection{Statistical Analysis}

Descriptive statistics and inter-correlation matrix were calculated. Inter-correlation matrix was built for all variables included in the study. The correlation between the perception of procedural justice and affective commitment was measured controlling those employees having low versus high EI. The exchange ideology score was divided into a dichotomous variable $(0$, and 1$)$ where people who scored above 60 percentiles were considered to have strong exchange ideology and people who scored below 60 percentile were defined as having weak exchange ideology.

Hierarchical moderated multiple regression analysis was used to test the hypothesis. In the first block the control variables were entered, in the second block procedural justice, in the third step exchange ideology and in the fourth step an interaction term between procedural justice and EI was entered.

\section{Results}

Table 1. Descriptive statistics and inter-correlation matrix of the measurement scales

\begin{tabular}{|c|c|c|c|c|c|c|c|c|}
\hline \multicolumn{4}{|c|}{ Descriptive statistics } & \multicolumn{5}{|c|}{ Inter-correlation matrix (Pearson correlation coefficient) } \\
\hline & Mean & SD & Range & & & & & \\
\hline Affective commitment & 2.8 & 1.1 & $1-6$ & 1 & & & & \\
\hline Procedural justice & 3.6 & 0.8 & $1-6$ & .016 & 1 & & & \\
\hline Exchange Ideology & 3.2 & 0.5 & $1-8$ & $-.066-$ & .173 & 1 & & \\
\hline Age & 32.3 & 0.7 & $18-45$ & .092 & .183 & $.299^{* *}$ & 1 & \\
\hline Sex & 1.6 & 0.5 & $1-2$ & $.375^{* *}$ & $-.334-^{* *}$ & $-.079-$ & .118 & 1 \\
\hline Job level & 1.7 & 0.9 & $1-4$ & $-.005-$ & $.262^{*}$ & $.343^{* *}$ & $.687^{* *}$ & -.125 \\
\hline
\end{tabular}

**. Correlation is significant at the 0.01 level (2-tailed).

*. Correlation is significant at the 0.05 level (2-tailed).

Table 1 shows that there is no significant correlation between the respondents' perception of procedural justice and their affective commitment to their organizations.

Exchange ideology is not correlated to affective commitment either. Age is positively correlated to exchange ideology $(\mathrm{r}=0.30)$. Females have more affective commitment $(\mathrm{r}=0.33)$ and males have more perception of procedural justice $(\mathrm{r}=0.38)$. The higher the job level, the higher the procedural justice, and exchange ideology $(\mathrm{r}=0.26,0.34$ respectively). 


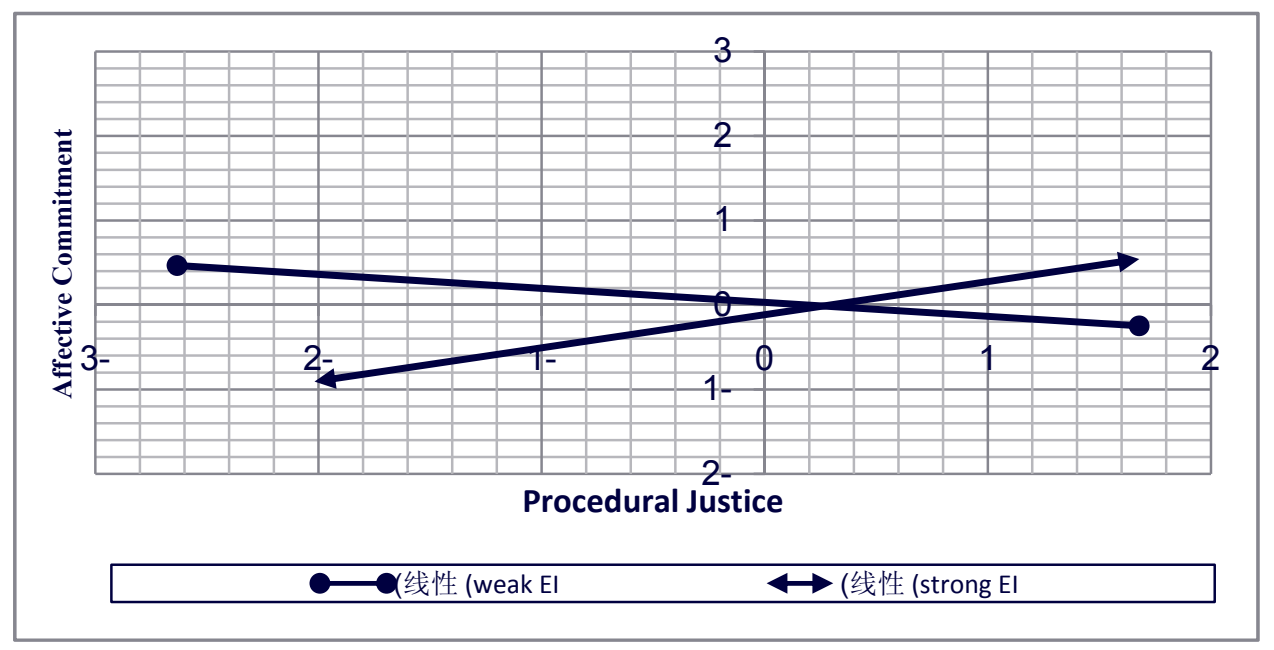

Figure 1. Affective commitment Z-scores regressed on procedural justice Z-scores: in week EI and Strong EI groups

To explore the relationship between procedural justice and affective commitment in the employees who have weak exchange ideology, the correlation coefficient was measured separately for those with weak exchange ideology $(r=-0.18, p>0.05)$ and for those who have strong exchange ideology $(r=0.33, \mathrm{P}<0.05)$ (figure 1$)$.

This indicates that there is a significant moderate positive correlation between procedural justice and affective commitment in the group of people who have strong EI. While those with weak EI, their affective commitment is not correlated to their perception of procedural justice. The exchange ideology and procedural justice scores were standardized to $\mathrm{Z}$ scores for easy comparison. The weak exchange ideology was defined as having EI score below 3.25 out of 6 . Strong exchange ideology was defined as having EI score over 3.25 out of 6 .

Table 2. Hierarchical moderated multiple regression results: dependent variable is affective commitment

\begin{tabular}{|c|c|c|c|}
\hline & $\mathbf{B}^{x}$ & $\mathbf{R}^{2}$ & $\Delta R^{2}$ \\
\hline \multicolumn{4}{|l|}{ Step 1} \\
\hline Lowest age group & - & & \\
\hline Middle age group & 0.50 & & \\
\hline Highest age group & -0.01 & & \\
\hline Sex & 0.88 & & \\
\hline Level & -0.06 & & \\
\hline$F(4,86)=4.9, P<0.001$ & & 0.19 & $0.19^{*}$ \\
\hline \multicolumn{4}{|l|}{ Step 2} \\
\hline Procedural justice & 0.22 & & \\
\hline$F(5,85)=4.9, P<0.001$ & & 0.22 & $0.03 *$ \\
\hline \multicolumn{4}{|l|}{ Step 3} \\
\hline Exchange ideology & -0.103 & & \\
\hline$F(6,84)=4.2, P<0.001$ & & 0.23 & 0.01 * \\
\hline \multicolumn{4}{|l|}{ Step 4} \\
\hline Procedural justice* exchange ideology & 0.01 & & \\
\hline$F(7,83)=4.2, P<0.001$ & & 0.26 & $0.03 *$ \\
\hline
\end{tabular}

$* \mathrm{P}<0.001$; $¥$ Unstandardized coefficients were reported.

Table two shows the regression results. The three scores (procedural justice, exchange ideology and affective commitment) were standardized to Z-score before entering the regression model to be able to compare the coefficients. 
The hierarchical model was built on four steps. With respect to step one, the control variables explained a significant amount of variability of the affective commitment score $\left(\mathrm{R}^{2}=0.19, \mathrm{P}<0.05\right)$. In the second step the procedural justice score explained more variance in commitment level $\left(\Delta \mathrm{R}^{2}=0.03 \mathrm{P}<0.05\right)$. Exchange ideology explained the extra $3 \%$ of the variance in the third step $\left(\Delta \mathrm{R}^{2}=0.03 \mathrm{P}<0.05\right)$. In the fourth step the interaction between procedural justice and exchange ideology explained the extra $6 \%$ of the variance in the affective commitment $\left(\Delta \mathrm{R}^{2}=0.06, \mathrm{P}<0.05\right)$.

\section{Discussion}

The results of this paper indicated correlation coefficients between employees' organizational justice perceptions and employees' affective commitment were not statistically significant. The paper also revealed that exchange ideology was not correlated with affective commitment. This result contradicts the finding of Witt et al (2001). On the other hand, there was significant moderate positive correlation between procedural justice and affective commitment among the Saudi nationals who have strong EI, when compared with those who had weak EI. These results are consistent with the findings of Ponnu and Chauah (2010). The results also indicated that older Saudi nationals were more committed than younger nationals while Saudi female employees were more committed towards their organizations than their male counterparts. These results are consistent with the findings of Witt et al. (2001).

One possible explanation of these mixed results (in comparison to prior studies) is that local culture has its direct and indirect impact on how individuals perceive procedural justice and the extent to which it is important in their work environment. Greenberg (2001) revealed that perceptions of justice are norm-based. Therefore, perceptions of justice would differ globally according to ethnic groups and different cultures that entail different values.

Saudi culture is dominated by certain values that are perceived as important such as respect, honesty, courtesy, and being just and fair, which are enforced by Islamic teachings.

Elamin and Alomain (2011) explained the relationship of procedural justice perceptions and affective commitment based on the mediating effect of Islamic teachings.

The results of the paper may provide managers with valuable insights on determinants of Saudi employees' commitment and retention; to assist them in formulating appropriate policies and procedures to manage their organizations.

\subsection{Managerial Implications}

Employees perceiving procedural justice would become more inclined to become affectively committed towards their organizations, and in turn less reluctant to leave their organizations. According to this study, the perception of procedural justice had a stronger effect on older male employees than on females. Also younger employees were less committed toward their organizations. Females were more committed toward their organizations regardless of their perceptions of procedural justice.

The results of this study should be read with caution since there are other social pressures to consider when examining such a relationship, in a context such as Saudi Arabia, where the collectivist and power distance Hofested (1980) has a greater effect on the way employees perceive fairness of procedures.

Saudi nationals are aware that the Saudization program imposed by the government will bring about procedural justice for Saudi employees by recruiting them and retaining their Saudi nationals Madhi and_Barrientos (2003). Because of this policy Saudi employees could not care the less about being affectively committed towards these organizations, since their promotions and employability will be a must in private sector companies because of the government policy.

\subsection{Future Research}

Future research may directly incorporate culture in general as a component of the model. For the Gulf states, it is recommended to incorporate certain cultural elements that are based on Islamic teachings. This may help explain more of the variance in procedural justice perception and organizational affective commitment.

\subsection{Research Limitations}

This paper is subject to some limitations. First, there is the limitation of the convenience sample (non-probability sample). A convenient sample may incorporate a selection bias and, therefore, influence the results of the study. A second limitation is attached to the use of questionnaires. Ibrahim, Al Sejini and Al-Qassimi (2004) indicated that the general assumption of using questionnaires is that people respond honestly to the questions. To the extent that this assumption holds, the results would not be affected. Violation of this 
assumption would affect the results. A third limitation of this paper had to do with my inability to assess response bias. However, the appropriate response rate may reduce the effect of this bias if it exists.

\section{References}

Abdullah, M. H., \& Shaw, J. D. (1999). Personal Factors and Organizational Commitment: Main and Interactive Effects in the United Arab Emirates. Journal of Managerial Issues, 11, 77-93

Allen, N. J., \& Meyer, J. P. (1990). The Measurement and Antecedents of Affective Continuance and Normative Commitment to the Organization. Journal of Occupational Psychology, 63, 1-18. http://dx.doi.org/10.1111/j.2044-8325.1990.tb00506.x

Blau, P. (1964). Exchange and Power in Social Life. New York, NY: Wiley.

Barling, J., \& Philips, M. (1993). Interactional, Formal, and Distributive Justice in the Workplace: An exploratory study. The Journal of Psychology, 127, 649-656. http://dx.doi.org/10.1080/00223980.1993.9914904

Cowherd \& Levine. (1992). Product Quality and Pay Equity Between Lower-Level Employees and Top Management: an Investigation of Distributive Justice theory. Administrative Science Quarterly, 37(2), 302-20. http://dx.doi.org/10.2307/2393226

Cropanzano, R., Howes, C., Grandey, A. A., \& Toth, P. (1997). The Relationship of Organizational Politics and Support to Work Behaviors, Attitudes, and Stress. Journal of Organizational Behavior, 18, 159-180. http://dx.doi.org/10.1002/(SICI)1099-1379(199703)18:2<159::AID-JOB795>3.0.CO;2-D

Cropanzano, R., \& Greenberg, J. (1997). Progress on Organizational Justice: Tunneling Through the Maze. In Cooper, C. L., \& Robertson, I. T. (Eds.), International Review of Industrial and Organizational Psychology (pp. 317-372). New York: Wiley and Sons.

Eisenberger, R., Huntington, R., Hutchison, S., \& Sowa, D. (1986). Perceived Organizational Support. Journal of Applied Psychology, 71(3) 500-507. http://dx.doi.org/10.1037/0021-9010.71.3.500

Elamin, A., \& Alomain, N. (2011). Does Organizational Justice Influence Job satisfaction Self -Perceived Performance in Saudi Arabia Work Environment? Journal of International Management Review, 7(1), 38-49.

Fakeeh, M. S. (2009). Saudization as a Solution for Unemployment. The Case of Jeddah Western Region. Submitted in Fulfillment of the Requirements of the Degree of Doctorate of Business Administration. University of Glasgow: UK.

Greenberg, J. (2001). The Seven Loose Can(n)ons of Organizational Justice. In Greenberg, J., \& Cropanzano, R. (Eds.), Advances in Organizational Justice (pp. 245-271). Stanford University Press. Stanford. CA.

Griffeth \& Hom. (1995). Employee Turnover. OH: South Western College Publishing.

Harrison, J. K., \& Hubbard, R. (1998). Antecedents to Organizational Commitment Among Mexican Employees of a U.S. firm in Mexico. Journal of Social Psychology, 138(5), 609-623. http://dx.doi.org/10.1080/00224549809600416

Hofstede, G. (1980). Culture's Consequences: International Differences in Work-Related Values. CA: Sage, Beverly Hills.

Ibrahim, M. E., Al-Sejini, S., \& Al-Qassimi, O. A. (2004). Job Satisfaction and Performance of Government Employees in UAE. Journal of Management Research, 4(1), 1-12.

Korsgaard, M. A., Schweiger, D. M., \& Sapienza, H. J. (1995). Building Commitment, Attachment, and Trust in Strategic Decision-making Team: The Role of Procedural Justice. Academy of Management Journal, 38(1), 60-84. http://dx.doi.org/10.2307/256728

Leung, K., \& Stephan, W. G. (2001). Social Justice From a Cultural Perspective. In Matsumoto, D. (Ed), The Handbook of Culture and Psychology (pp. 375-378). Oxford University press: New York.

Madhi, S. T., \& Barrientos, A. (2003). Saudization and Employment in Saudi Arabia. Career Development International, 8(2), 70-77. http://dx.doi.org/10.1108/13620430310465471

Masterson, S. S., Lewis, K., Goldman, B. M., \& Taylor, M. S. (2000). Integrating Justice and Social Exchange: The Differing Effects of Fair Procedures and Treatment on Work Relationship. Academy of Management Journal, 43(4), 738-748. http://dx.doi.org/10.2307/1556364 
Meyer, J. P., \& Allen, N. J. (1991). A Three-Component Conceptualization of Organizational Commitment. Human Resource Management Review, 1(28), 61-89. http://dx.doi.org/10.1016/1053-4822(91)90011-Z

Moorman, R. H. (1991). Relationship Between Organizational Justice and Organizational Citizenship Behaviors: Do Fairness Perceptions Influence Employee Citizenship? Journal of Applied Psychology, 76(6), 845-855. http://dx.doi.org/10.1037/0021-9010.76.6.845

Moorman, R. H., Blakely, G. L., \& Niehoff, B. P. (1998). Does Perceived Organizational Support Mediate the Relationship Between Procedural Justice and Organizational Citizenship Behavior? Academy of Management Journal, 41(3), 351. http://dx.doi.org/10.2307/256913

Mowday R. T., Steers, R. M., \& Porter, L. W. (1979). The Measurement of Organizational Commitment. Journal of Vocational Behavior, 14(2), 224-247. http://dx.doi.org/10.1016/0001-8791(79)90072-1

Ponn, C. H., \& Chuan, C. C. (2010). Organizational Commitment, Organizational Justice and Employee Turnover in Malaysia. African Journal of Business Management, 4(13), 2676-2692.

Porter, L. W., Steers, R. M., Mowday, R. P., \& Boulian, P. V. (1974). Organizational Commitment, Job Satisfaction, and Turnover among Psychiatric Technicians. Journal of Applied Psychology, 59(5), 603-609. http://dx.doi.org/10.1037/h0037335

Rhoades, L., Eisenberger, R., \& Armeli, S. (2001). Affective Commitment to the Organization: the Contribution of Perceived Organizational Support. Journal of Applied Psychology, 86(5), 825-836. http://dx.doi.org/10.1037/0021-9010.86.5.825

Scandura. T. A., \& Lankan, M. J. (1997). Relationships of Gender, Family Responsibility and Flexible Work Hours to Organizational Commitment and Job Satisfaction. Journal of Organizational Behavior, 18(4), 377-391. http://dx.doi.org/10.1002/(SICI)1099-1379(199707)18:4<377::AID-JOB807>3.0.CO;2-1

Shore, L. M., Barksdale, K., \& Shore, T. H. (1995). Managerial Perceptions of Employee Commitment to the Organization. Academy of Management Journal, 38(6), 1593-1615. http://dx.doi.org/10.2307/256845

Shore, L. M., \& Shore, T. H. (1995). Perceived Organizational Support and Organizational Justice. In R. Cropanzano \& K. M. Kacmar (Eds.), Organizational Politics, Justice, and Support: Managing Social Climate at work (pp. 149-164). Westport, CT: Quorum Press.

Shore, L. M., \& Wayne, S. J. (1993). Commitment and Employee Behavior: Comparison of Affective Commitment and Continuance Commitment with Perceived Organizational Support. Journal of Applied Psychology, 78(5), 774-780. http://dx.doi.org/10.1037/0021-9010.78.5.774

Tyler, T. R., \& Lind, E. A. (1992). A Relational Model of Authority in Groups. In Zanna, M. (Ed.), Advances in Experimental Social Psychology (pp. 115-191). New York; Academic.

Witt, L. A., Kacmar, M. K., \& Andrews, M. C. (2001). The Interactive Effects of Procedural Justice and Exchange Ideology on Supervisor-rated Commitment. Journal of Organizational Behavior, 22(5), 505-515. http://dx.doi.org/10.1002/job.99

\section{Copyrights}

Copyright for this article is retained by the author(s), with first publication rights granted to the journal.

This is an open-access article distributed under the terms and conditions of the Creative Commons Attribution license (http://creativecommons.org/licenses/by/3.0/). 